\title{
Ureteroscopic laser treatment of upper urinary tract neoplasms.
}

\author{
Demetrius H. Bagley \\ Thomas Jefferson University \\ Michael Grasso \\ Medical College of New York
}

Follow this and additional works at: https://jdc.jefferson.edu/radiologyfp

Part of the Radiology Commons

Let us know how access to this document benefits you

\section{Recommended Citation}

Bagley, Demetrius H. and Grasso, Michael, "Ureteroscopic laser treatment of upper urinary tract neoplasms." (2010). Department of Radiology Faculty Papers. Paper 10.

https://jdc.jefferson.edu/radiologyfp/10

This Article is brought to you for free and open access by the Jefferson Digital Commons. The Jefferson Digital Commons is a service of Thomas Jefferson University's Center for Teaching and Learning (CTL). The Commons is a showcase for Jefferson books and journals, peer-reviewed scholarly publications, unique historical collections from the University archives, and teaching tools. The Jefferson Digital Commons allows researchers and interested readers anywhere in the world to learn about and keep up to date with Jefferson scholarship. This article has been accepted for inclusion in Department of Radiology Faculty Papers by an authorized administrator of the Jefferson Digital Commons. For more information, please contact: JeffersonDigitalCommons@jefferson.edu. 


\title{
As submitted to:
}

World Journal of Urology

\author{
And later published as:
}

“URETEROSCOPIC LASER TREATMENT OF UPPER

\author{
URINARY TRACT NEOPLASMS”
}

Volume 28, Issue 2, 2010, Pages 143-149

DOI: 10.1007/s00345-010-0525-7

Demetrius H. Bagley, M.D. , The Nathan Lewis Hatfield Professor of Urology Professor of Radiology, Thomas Jefferson University, Philadelphia, PA USA*

Michael Grasso, III, M.D., Chairman, Department of Urology,

St. Vincent's Hospital, New York, NY USA

Professor and Vice Chairman, Department of Urology, Medical College of New York

${ }^{*}$ Contact:

Demetrius H. Bagley, M.D. 
Department of Urology

Thomas Jefferson University

1025 Walnut Street

Room 1108

Philadelphia, PA 19107 USA

Phone: 215-955-2662

Fax: 215 923-1884

Email: Demetrius.Bagley@jefferson.edu

Keywords: Upper tract TCC, Laser treatment, ureteroscopy, neoplasms 


\section{ABSTRACT}

Background: Endoscopic management of upper urinary tract transitional cell carcinoma has assumed an important role in diagnosis and treatment. The introduction of small diameter rigid and flexible ureteroscopes has permitted access to the upper tract. Biopsy techniques have been developed for accurate diagnosis and the addition of lasers has given the urologists an excellent tool for treatment.

Methods: Medical literature available relative to the endoscopic laser treatment of upper tract neoplasms has been reviewed.

Results: Ureteroscopic treatment has been characterized by good success with high recurrence rates, both in the upper tract and the bladder. Bladder recurrence rates are similar to those seen after surgical treatment of upper tract tumors. Surveillance has been ureteroscopic since the other diagnostic options are inadequate. The holmium and neodymium:YAG lasers are the devices most commonly used now for the endoscopic treatment of upper tract tumors. Conclusion: Ureteroscopic treatment of upper tract neoplasms usually with ablation and resection using the neodymium and holmium:YAG lasers is a current acceptable procedure. This should be reconsidered as one of the options in tumor treatment. 
Transitional cell carcinoma of the upper urinary tract is an uncommon lesion but is a potentially lethal tumor requiring treatment. Treatment has traditionally been surgical, either with nephroureterectomy or for low grade distal ureteral tumors, distal ureterectomy, including a wide bladder cuff around the orifice. ${ }^{1,2}$

The development of small, rigid and flexible ureteroscopes in the early 1980's became possible with the introduction of fiberoptic illumination and imaging. These instruments have permitted routine access to the entire upper collecting system ${ }^{3}$ and have revolutionized the treatment of calculi and neoplasms. The Holmium:YAG and the Neodymium:YAG lasers are both effective for neoplasms and can be delivered through small flexible fibers. ${ }^{4,5}$

\section{INSTRUMENTS}

\section{Endoscopes}

Small rigid endoscopes are available in single and dual channel designs ranging from approximately 5 to $9+\mathrm{French}$ tip diameter (most commonly $\sim 7 \mathrm{~F}$ with a $3.6 \mathrm{~F}$ channel). ${ }^{6}$ Dual channel designs allow for simultaneous irrigation and placement of a working device. These endoscopes can be passed easily under direct vision into the distal ureter to inspect that area without any prior instrumentation (i.e. termed the "no touch" inspection technique), but cannot adequately inspect the renal pelvis or intrarenal collecting system.

Actively deflectable, flexible ureteroscopes were developed to access the intrarenal collecting system and proximal ureter atraumatically. They are available in single channel designs from 7.4 to $9+F$ while a larger endoscope is available with dual channels. The smaller diameter endoscopes can also be placed under direct vision frequently without trauma of guidewire introduction, thus, employing a "no touch" technique. To inspect the lower pole calyx in most kidneys, the ureteroscope must deflect $170^{\circ}$ but to compensate for loss of deflection with working instruments in the channel, the active tip deflection has been increased to nearly $300^{\circ}$ in most ureteroscopes. 
Recently, flexible ureteroscopes have been constructed with digital imaging chips at the tip. These produce an excellent endoscopic image with better resolution but suffer from a larger overall diameter of nearly $10 \mathrm{~F}$ as well as limited deflectability. Although it has been suggested that these instruments will have greater durability, this remains to be demonstrated.

\section{Lasers}

The Holmium and Nd:YAG lasers are effective devices for treating neoplasms throughout the urinary tract. The characteristics of these lasers are listed in Table 1 . The $\mathrm{Nd}: Y A G$ at a wavelength of $1064 \mathrm{~nm}$ destroys tissue with coagulation. It has a depth of penetration up to several millimeters (5-10) in tissue or water and therefore, direct contact of the fiber with the neoplasm is not necessary. It is effective in treating tumors up to centimeters in diameter. However, it is difficult to judge the depth of penetration during treatment. It can be combined with techniques to remove the coagulated tissue.

The Holmium YAG laser is a pulsed device with a wavelength of $2100 \mathrm{~nm}$. It can cause coagulation at lower energies and higher pulse durations and can ablate the tissue coagulated either with the holmium or the Nd:YAG laser. The Holmium energy penetrates tissue only $<0.4$ $\mathrm{mm}$ and therefore its effect is relatively superficial and is endoscopically visible.

Fibers of various sizes can be used with either laser. Each fiber consists of a central core and a cladding with resultant diameter and deflection characteristics. The most commonly used fibers are 200 or $365 \mu$ diameter. The smaller fiber is more flexible but is a less efficient ablator of tissue since it has an exponentially smaller spot size, and, with the holmium:YAG, a much smaller vaporization bubble.

Other lasers, like the diode and the thulium, can be delivered with flexible fibers but have not yet been used and/or reported in significant clinical series of patients with upper urinary tract urothelial tumors. 


\section{Biopsy Devices}

Tissue samples can be taken with several different devices, indwelling baskets, forceps, graspers, snares and brushes. The most effective basket is a stainless steel flat wire design which can be closed to trap the tissue in the angle between the wires.

Several designs of $1 \mathrm{~mm}$ diameter cup forceps are available and are useful in sampling flat or solid, nonpapillary lesions with a small sample fully contained within the cup, the device can be withdrawn through the working channel and replaced to obtain multiple tissue fragments. The stiffness of the shaft of the forceps often prohibits endoscope deflection of more than 90 to $100^{\circ}$ depending on the endoscope used. The other instruments are relatively ineffective in obtaining tissue and are rarely used.

\section{TECHNIQUES}

Suspected upper tract neoplasms are often evaluated with contrast CT scan, (CT urogram, CTU), intravenous pyelogram or retrograde ureteropyelogram. The suspected lesion is then diagnosed endoscopically. The appearance is similar to that of urothelial tumors within the bladder and may be papillary, sessile or flat. In one series, visual inspection alone was only $70 \%$ accurate in determining the malignancy or grade of a neoplasm in the upper tract. ${ }^{7}$

It is also important to obtain a sample of tissue for pathologic diagnosis, since the grade of the tumor is important in the decision process for treatment. Papillary lesions can be sampled with a stainless steel flat wire basket which is applied around the tumor and closed snugly but not completely. It is then used to avulse a piece of tissue. The entire unit of tumor, basket and endoscope are removed to preserve the largest piece of tissue available. Samples should not be withdrawn with a basket through the channel since most of the sample would be sheared off and lost.

Alternatively, for smaller, sessile or flat lesions, a cup forceps is used. Multiple samples should be taken. If the entire sample is contained within the cup, it can be withdrawn through 
the channel of the ureteroscope. If there is a larger piece extending beyond the extent of the cup, then again the entire unit of tumor, forceps and endoscope should be removed to maintain the largest sample.

The tissue sample is delivered directly into a collection tube with a small aliquot of saline. If there will be a delay in delivering the sample to the cytopathology laboratory, the appropriate amount of cytologic preservative is added. All tissue samples are processed as cytology specimens to avoid loss of tissue in preparation. ${ }^{8}$ A cell block can be made for macroscopically visibly evident samples.

After adequate sampling, the tumor can be treated. Very small (1 to $2 \mathrm{~mm}$ ) lesions can be treated effectively and completely with the holmium laser using few pulses. We commonly prefer to use the holmium laser for all ureteral lesions because of the lower risk of ureteral stricture with this controlled energy source. Localized tissue reaction with subsequent stricture may result from treatment of larger lesions or those encompassing more than one-half circumference of the ureter or from the use of the neodymium:YAG laser which causes a deeper tissue effect. (Table 1$)^{9}$

Specific capabilities of the Ho or Nd:YAG lasers can be utilized to maximize coagulation or ablation of neoplasms throughout the bladder or upper tract. Selection of the laser depends on the size and location of the lesion. The holmium laser alone can coagulate tumors with the maximum coagulative effect given by defocussing the laser beam on the tissue. Close approximation of the tip of the fiber or contact with the tissue gives a more ablative effect and removes tissue. Generally, there is less bleeding with the coagulative technique.

Specific holmium lasers have variable pulse durations which can be employed to obtain unique tissue effects. The longer pulse provides the same energy per pulse giving less intensity and improved coagulation. It retains some ablative properties while the shorter pulse duration maximizes the ablative effect. 
The Neodymium YAG laser is a continuous wave device producing a wavelength which penetrates more deeply into tissue. Its major effect is coagulative and is very useful for deeper coagulation of larger tumors. It produces no ablation and the resultant coagulated tissue can be removed mechanically or with a Ho laser. Care must be taken with the Nd:YAG laser to avoid treating the ureteral wall circumferentially since it penetrates deeply and can result in a stricture.

Within the renal pelvis, the energy choice depends mainly upon the size of the lesion. Larger vascular tumors $(>1 \mathrm{~cm})$ can be coagulated initially with the neodymium:YAG and then ablated and cleared with the holmium when a combination laser is available. These lesions can also be treated with the holmium laser alone. Lower holmium energy tends to maximize the coagulative effect and minimize the risk of bleeding (e.g. 0.5 to 0.6 joules and 5 hertz). When a laser with a variable pulse duration is available, the longer duration is used to maximize the coagulative effect and minimize bleeding.

Adequate removal of neoplastic tissue without penetration of the pelvis or the ureter is highly technique dependent. The fiber of the holmium laser is applied only where the coagulative or ablative effect is desired. When the tumor partially obscures the ureter or renal pelvis, the laser is moved in an arc along the normal contour at the base of the neoplasm. It is helpful to initiate resection at the more proximal portion of the tissue and then work distally. In this way, it is possible to avoid advancing the fiber into the mucosa or wall of the ureter or renal pelvis.

Some intrarenal locations are inherently difficult to treat with lasers. This occurs most commonly on the medial wall of the lower infundibulum. In these unusual situations, if it is impossible to reach with the 200 micron fiber, the flexible ureteroscope may deflect further with a $2 \mathrm{~F}$ Bugbee electrode. This device also has the advantage of coagulation from the side of the tip. As opposed to laser fibers, it is not necessary to point the device directly at the tissue. 


\section{CLINICAL RESULTS}

Several papers have summarized reports of ureteroscopic treatment of upper tract transitional cell carcinoma (UUTTCC). ${ }^{10,11,12}$ Many of these papers have used lasers as one of the endoscopic ablative devices for treatment. The earliest series, before the availability of the holmium laser, used electrocautery or electroresection while some were limited to rigid endoscopes. These reports are characterized by a high success rate for ablation of tumor with preservation of renal units. However, there is a high recurrence rate of the neoplasms. Kidneys have been preserved in approximately $70 \%$ of patients, while recurrences have ranged from 20 $88 \%$. Therefore, endoscopic surveillance has an essential role in the treatment and follow up process after ureteroscopic treatment of UTTCC.

New or recurrent bladder tumors are also common after the treatment of an upper urinary tract carcinoma (Table 2). New or recurrent bladder tumors were seen after ureteroscopic treatment in $40.5 \%$ of patients in series up to $2001 .{ }^{13}$ Among more current series, there is also a wide range of bladder tumors appearing in $20-44 \%$ of patients. In comparison, bladder tumors have been reported to occur in from 15 to $45 \%$ of patients treated with open surgical nephroureterectomy and from 10 to $55 \%$ after laparoscopic nephroureterectomy. It is difficult to make direct comparisons, since the grade and stage of tumors, the intensity of endoscopic follow up and particularly the duration of follow up varies so widely. The rate of bladder tumors from these rough comparisons suggests that the rate of new or recurrent bladder tumors after endoscopic resection is not out of the range seen with nephroureterectomy.

By far the most common complication after ureteroscopic treatment is ureteral stricture. This can occur either at the site of resection of a ureteral tumor or at other sites throughout the ureter. In a combined series a rate of $13.7 \%$ was reported in $2001 .{ }^{13}$ It is impossible to separate the strictures occurring in patients treated with lasers since all series include some treated with electrofulguration. The overall stricture rate in the series available is $12.7 \%$, which is 
considerably higher than the rate of $<1 \%$ seen after the ureteroscopic treatment of ureteral stones. $^{30}$ (Table 3)

\section{DISCUSSION}

The standard treatment of upper tract neoplasms has been nephroureterectomy with excision of a bladder cuff. Studies in the 1970's demonstrated the feasibility of distal ureterectomy to treat low grade distal ureteral neoplasms. Therapy was less successful for renal pelvic and proximal ureteral lesions suggesting a "downstream" effect. ${ }^{31,32}$

The next developmental step was to treat upper urinary tract tumors endoscopically. Based on the established endoscopic treatment of bladder tumors, the application of these techniques became limited only by the instrumentation available. This concept became a reality as appropriate ureteroscopes became available. ${ }^{33,34}$ The refinement of these endoscopes has made it possible to reach the entire intrarenal collecting system in most patients.

Similarly, instruments and techniques were developed to sample and treat upper tract tumors. Accurate diagnosis has improved by using cytologic techniques with cell blocks to identify larger samples. ${ }^{35,36}$ Ureteroscopic biopsies have been shown to have a high, but not perfect accuracy ranging from 80 to $90 \% .^{37,14}$

Endoscopic access to the upper tract presents the opportunity for treatment. The first instruments for ablation and coagulation were 2 or $3 F$ electrodes. In the series cited, patients dating from the early 1980's were treated electrosurgically and often subsequently grouped with and then treated with lasers as they recurred during long term follow up. Both the holmium:YAG and neodymium:YAG lasers can be delivered through small flexible fibers to the vast majority of surfaces within the upper collecting system.

The Neodymium:YAG laser has been demonstrated to be an effective mechanism for the endoscopic treatment of bladder tumors. In a small series, it was shown to coagulate upper

tract neoplasms successfully with an open surgical approach. ${ }^{38}$ The Neodymium:YAG laser can 
effectively coagulate tissue, but it may be difficult to determine the depth of coagulation and the treated tissue remains in place and is not cleared. This is a minimal problem in the bladder but in the ureter or the renal pelvis, the coagulated tissue obscures deeper portions of the tumor which may be viable. This treated tissue must be removed mechanically or by ablation with the holmium laser. The holmium:YAG laser can also coagulate tissue primarily, although less efficiently. Lengthening the holmium pulse duration improves the coagulative effect. Combining the Ho and Nd:YAG lasers gives maximal coagulative and ablative effects, delivering a more controlled coagulation and ablation of urothelial tumors than that delivered with a small cautery electrode.

The aim of the conservative management of upper tract neoplasms is to preserve renal function. This may be considered imperative or strongly indicated in patients with a solitary kidney, solitary functioning kidney or limited renal function. The alternative of nephroureterectomy with subsequent dialysis, and even possible later transplantation, must be considered and offered to the patient. There is a high morbidity and also mortality associated with dialysis. In a recent series of 128 hemodialysis patients with a mean age of 61 years, the 3 year survival was only $55 \% .{ }^{39}$ Data from end stage renal disease database shows a decrease in survival in older patients. ${ }^{40}$ Five year survival over the last cited year (2001) was 30.7\% for patients ages $65-69,20.2 \%$ for those $70-79$ and dropped to $9.6 \%$ at $\geq 80$ years.

Recently, the risks of chronic renal failure associated with a solitary kidney have become evident. ${ }^{41}$ There is interest in for maintaining renal function and avoiding development of an anephric state. Much of this emphasis has been directed toward the development of laparoscopic partial nephrectomy. However, the same arguments can be applied to UUTTCC.

The treatment of upper tract neoplasm with ureteroscopic techniques is quite successful. Low grade tumors carry a low mortality with treatment by many means including ureteroscopy. High grade tumors have a more pessimistic prognosis in general, with lower survival rates after either nephroureterectomy or endoscopic treatment. When high grade tumors are treated 
ureteroscopically, often palliatively, most patients maintain renal function with acceptable local control. Overall, ureteroscopic treatment of upper tract tumors has an excellent disease specific survival and results in approximately $70 \%$ renal maintenance. ${ }^{42}$

There are also both recognized and potential risks from ureteroscopic treatment. There remains a very high recurrence rate in most series ranging from 20 to $85 \%$. Generally, the more recent reports have higher recurrence rates. This may be related to the longer follow up in these series. Alternatively, it may be related to the treatment of larger and more proximal neoplasms which in a surgical series have been shown to be more likely to have distal recurrences. The progression of grade is also possible approximating $10 \%$ in a large series. Therefore, it is essential that treated patients have endoscopic follow up since the noninvasive modalities of urinalysis, urinary cytology or FISH studies are inadequate to define recurrence. ${ }^{43,44,45}$

Cost has become an important consideration in guiding treatment. Repetitive treatment or repetitive endoscopic surveillance can be an ongoing expense for health systems. In the US, the high cost associated with transplantation, or the even greater costs of hemodialysis makes endoscopic treatment and surveillance an attractive alternative. In comparison, in the medicare payment system, hemodialysis was the most expensive while successful ureteroscopic treatment with surveillance was the least expensive. There can be expected to be variations in different national health systems. ${ }^{42}$

There remain many unknown factors involved in the endoscopic therapy of upper tract TCC. For example, it is impossible to determine the exact stage of the neoplasm. Several series have shown that the stage is related to the grade. ${ }^{46}$ The latter can be obtained from ureteroscopic biopsy with a reasonably high accuracy when compared with the grade seen on surgical specimens. Other staging studies, such as CT scanning, can be useful but do not have sufficient resolution for lower stages. Currently, tumor grade remains the best prognosticator.

The sources of urothelial tumor recurrences are unknown. It may be related to the field change in patients with urothelial carcinoma. This is supported from the known 5 to $10 \%$ 
bilaterality of upper tract neoplasms. Similarly, the high risk of new or recurrent tumors at similar rates after ureteroscopic treatment or open or laparoscopic nephroureterectomy suggests a field change rather than seeding. However, cytologically intact cells can be seen in the irrigant after endoscopic laser treatment. ${ }^{47}$ Their role in recurrence is unknown. Another unknown is the process of treatment itself. It is impossible to determine the adequacy of coagulation and ablation visually. For example, the depth of penetration from the neodymium:YAG laser is never certain except by visual inspection, which is inadequate. Similarly, the extent or presence of invasion of the neoplasm is impossible to determine.

Adjuvant therapy has been considered as a means to reduce recurrence. Agents such as topical Mitomycin, used after endoscopic resection, may have a role in decreasing recurrence in the upper tract as it has in the bladder. ${ }^{48}$ It has been employed in two short series. ${ }^{49,50}$ It has been demonstrated to be tolerated but there are insufficient data to determine its efficacy.

\section{CONCLUSION}

Currently, ureteroscopic laser resection of upper tract neoplasms is an acceptable option for treatment. It is an excellent first choice for patients with a solitary kidney, compromised contralateral kidney or impaired renal function. It has been used with very good success electively in patients with small low grade tumors and a normal contralateral kidney in an effort to preserve renal function. All patients must be followed endoscopically and must be willing to agree to endoscopic surveillance because of the high risk of recurrence in the upper tract and bladder. The holmium and neodymium:YAG lasers are presently the most commonly used devices. The laser combining Nd and Holmium:YAG is convenient and effective but the holmium:YAG lasers can be used alone, preferentially with the variable pulse duration. 


\section{$\underline{\text { References }}$}

1. Mazeman E: Les Tumeurs de la Voie Excretice Urinaire Superieure Calices, Bassinet, Uretere. Paris, Masson et Cie, Assoc Franc D’Urol, 1972.

2. Babayan RJ and Johnson DE : Primary carcinoma of the ureter. J Urol 123: 357-359, 1980.

3. Bagley, D.H., Huffman, J.L. and Lyon, E.S.: Combined rigid and flexible ureteropyeloscopy. J. Urol. 130: 243-244, 1983.

4. Schilling A., Bowering R. and Keiditisch E.: Use of the neodymium-YAG laser in the treatment of ureteral tumors and urethral condylomata acuminata. Clinical experience. Eur Urol 12 (suppl 1): 30-33, 1986.

5. Johnson DE: Use of the holmium:YAG (Ho:YAG) laser for treatment of superficial bladder carcinoma. Lasers Surg Med 14: 213-218, 1994.

6. Grasso M and Bagley DH: . A 7.5/8.2 F actively deflectable, flexible ureteroscope: a new device for both diagnostic and therapeutic upper urinary tract endoscopy. Urology 43: 435-441, 1994.

7. El-Hakim A, Weiss GH, Lee BR, Smith AD: Correlation of ureteroscopic appearance with histologic grade of upper tract transitional cell carcinoma. Urology 63: 647-650, 2004.

8. Tawfiek E.: Bibbo, M. and Bagley, D.H.: Ureteroscopic Biopsy: Technique and Specimen Preparation. Urology 50: 117-119, 1997.

9. Bagley $\mathrm{DH}$ : unpublished

10. Tawfiek ER and Bagley DH: Upper tract transitional cell carcinoma. Urology 50: $321-$ 329, 1997.

11. Argyropoulos AN and Tolley DA: Upper urinary tract transitional cell carcinoma: current treatment overview of minimally invasive approaches. BJU 99: 982-987, 2007.

12. Bader MJ, Stroka R, Gratzke $C$ et al: Laser therapy for upper urinary tract transitional cell carcinoma: Indications and management. Eur Urol 56: 65-71, 2009.

13. Chen $\mathrm{GL}$ and Bagley $\mathrm{DH}$ : Ureteroscopic surgery for upper tract transitional cell carcinoma: complications and management. J Endourol 15: 399-404, 2001.

14. Daneshmand S, Quek ML, Huffman JL: Endoscopic management of upper urinary tract transitional cell carcinoma. Cancer 98 (1): 55-60, 2003.

15. Thompson $\mathrm{RH}$, Krambeck $\mathrm{AE}$, Lohse $\mathrm{CM}$ et al: Elective endoscopic management of transitional cell carcinoma first diagnosed in the upper urinary tract. BJUI 102: 1107-1110 2008.

16. Sowter SJ, Ilie CP, Efthimiou I, Tolley DA: Endourologic management of patients with upper tract transitional cell carcinoma: Long term follow up in a single center. J Endourol 21(9): 1005-1009, 2007. 
17. Rassweiler JJ, Schulze M, Marrero R et al: Laparoscopic nephroureterectomy for upper urinary tract transitional cell carcinoma: is it better than open surgery. Eur Urol 46: 690-697, 2004.

18. Wolf JS, Dash A, Hollenbeck BK et al: Intermediate followup of hand-assisted laparoscopic nephroureterectomy for urothelial carcinoma: factors associated with outcomes. J Urol 173: 1102-1107, 2005.

19. Okegawa T, Odagane A, Ide S, et al: Oncological outcome of retroperitoneoscopic nephroureterectomy for upper urinary tract transitional cell carcinoma. Int J Urol 13: 493-497, 2006.

20. Tsujihata M, Nonomura N, Tsujimura A et al: Laparoscopic nephroureterectomy for upper tract transitional cell carcinoma: comparison of laparoscopic and open surgery. Eur Urol 49: 332-336, 2006.

21. Raman JD, Palese MA, Ng CK et al: Hand-assisted laparoscopic nephroureterectomy for upper urinary tract transitional cell carcinoma. J Soc Lap Surgeons 10: 432-438, 2006.

22. Chung SD, Chueh SC, Lai, MK et al.: Long term outcome of hand-assisted laparoscopic radical nephroureterectomy for upper tract urothelial carcinoma: Comparison with open surgery. J Endourol 21:595-599, 2007.

23. Manabe D, Saika T, Ebara S et al: Comparative study of oncologic outcome of laparoscopic nephroureterectomy and standard nephroureterectomy for upper urinary tract transitional cell carcinoma. Urology 69: 457-461, 2007.

24. Muntener M, Nielsen ME, Romero FR et al: Long-term oncologic outcome after laparoscopic radical nephroureterectomy for upper tract transitional cell carcinoma. Eur Urol 51: 1639-1644, 2007.

25. Roupret M, Hupertan V, Sanderson KM et al: Oncologic control after open or laparoscopic nephroureterectomy for upper urinary tract transitional cell carcinoma: a single center experience. Urology 69: 656-661, 2007.

26. Taweemonkongsap T, Nualyong C, Amornvesukit T et al: Outcomes of surgical treatment for upper urinary tract transitional cell carcinoma: Comparison of retroperitoneoscopic and open nephroureterectomy. World J Surg Oncol 6:1-7, 2008.

27. Waldert M, Remzi M, Klingler HC et al: The oncological results of laparoscopic nephroureterectomy for upper urinary tract transitional cell cancer are equal to those of open nephroureterectomy. BJU Int 103: 66-70, 2009.

28. Suh RS, Faerber GJ and Wolf JS: Predictive factors for applicability and success with endoscopic treatment of upper tract urothelial carcinoma. J Urol 170: 2209-2216, 2003.

29. Johnson GB, Fraiman M, Grasso M: Broadening Experience with Retrograde Endoscopic Management of Upper Urinary Tract Urothelial Malignancies. BJUI 95, Supp 2, 110-113, March 2005. 
30. Elashry OM, Elgamasy AK, Sabaa MA et al: Ureteroscopic management of lower ureteral calculi: A 15 year single centre experience. BJU Int 102: 1010-1017, 2008.

31. Mazeman E.: Tumors of the upper tract, calyces, renal pelvis and ureter. Eur Urol 2: 120-126, 1976.

32. Zincke $\mathrm{H}$ and Neves RJ: Feasibility of conservative surgery for transitional cell cancer of the upper urinary tract. Urol Clin North Am 11: 717-724, 1984.

33. Huffman JL, Bagley DH, Lyon ES, et al: Endoscopic diagnosis and treatment of upper tract urothelial tumors. A preliminary report. Cancer 55: 1422-1428, 1985.

34. Lyon ES: The birth of modern ureteroscopy: The Albona Jaybis Story. J Endourol 18:525-526, 2004.

35. Low RK, Moran ME and Anderson KR: Ureteroscopic cytologic diagnosis of upper tract lesions. J Endourol 7: 311-314, 1993.

36. Bagley DH, Kulp DA and Bibbo M: Ureteroscopci biopsy optimized by cytopathologic techniques. J Urol 151: 387A, 1994.

37. Keeley FX, Kulp DA, Bibbo M, McCue PA, Bagley DH: Diagnostic accuracy of ureteroscopic biopsy in upper tract transitional cell carcinoma. J Urol 157: 33-37, 1997.

38. Malloy TR: Laser treatment of ureter and upper collecting system, in Smith AD (ed): Lasers in Urologic Surgery. Chicago, Year Book, 1985, pp 82-93.

39 Qureshi AR, Alvesteran DA, Divino-Filhjc et al: Inflammation, malnutrition, cardiac diseases Predictors a mortality a hemodialysis patients. JM Soc Nephrol 13: S28, 2002.

40. National Kidney and Urologic Diseases Information Clearing House, National Institute of Diabetes and Digestive and Kidney Disease. National Institutes of Health, Bethseda, Maryland, $\mathrm{NIH}, 2008$.

41. Snow DC, Bhayani SB: Rapid communication: Chronic renal insufficiency after laparoscopic partial nephrectomy and radical nephrectomy for pathologic t1a lesions. J Endourol 22: 337-341, 2008.

42. Pak RW, Moskowitz EJ and Bagley $\mathrm{DH}$ : What is the cost of maintaining a kidney in upper tract transitional cell carcinoma? An Objective analysis of cost and survival. J Endourol. 23: 341-346, 2009.

43. Chen, GL, El-Gabry EA and Bagley DH: Surveillance of upper urinary tract transitional cell carcinoma: the role of ureteroscopy, retrograde pyelography, cytology and urinalysis. J Urol 164: 1901-1904, 2000.

44. Marin-Aguilera M, Mengual L, Ribal MJ et al : Utility of fluorescence in situ hybridization as a nonivasive technique in the diagnosis of upper urinary tract urothelial carcinoma. Eur Urol 51(2): 409-415, discussion 15, 2007.

45. Chen AA, Grasso $\mathrm{M}$ : Is there a role for FISH in the management and surveillance of patients with upper tract transitional cell carcinoma? J Endourol 22: 1371-1374, June 2008. 
46. Brown GA, Matin Surena, Buzby JE et al: Ability of clinical grade to predict final pathologic stage in upper urinary tract transitional cell carcinoma: implications for therapy. Urology 70:252-256, 2007.

47. Bagley $\mathrm{DH}$ and Bibbo M: unpublished observation.

48. Sylvester RJ, Oosterlinck W, Van der Meijden AP: A single immediate postoperative instillation of chemoterhapy decreaes the risk of recurrence in patients with TaT1 bladder cancer: A meta-analaysis of published results of randomized clinical trials. J Urol 171: 21862190, 2004.

49. Eastham JA and Huffman JL: Technique of mitomycin $\mathrm{C}$ instillation in the treatment of upper urinary tract urothelial tumors. J Urol 150: 324-325, 1993.

50. Keeley FX and Bagley $\mathrm{DH}$ : Adjuvant mitomycin $\mathrm{C}$ following endoscopic treatment of upper tract transitional cell carcinoma. J Urol. 158: 2074-2077, 1997. 
Table 1

Use of Ho and ND:YAG Laser for Ureteroscopic Treatment of UTTCC*

\begin{tabular}{|c|c|c|c|}
\hline \multirow{5}{*}{$\begin{array}{l}\text { Laser } \\
\mathrm{Ho} \\
\mathrm{Nd} \\
\mathrm{Ho} \& \mathrm{Nd}\end{array}$} & \multicolumn{3}{|c|}{ Site } \\
\hline & Kidney & Ureter & Bladder \\
\hline & 8 & 40 & 5 \\
\hline & 2 & -- & 6 \\
\hline & 34 & 2 & 22 \\
\hline & $\begin{array}{l}\text { Total } 77 \\
\text { Over } 1\end{array}$ & $\begin{array}{l}\text { dures (s } \\
1 / 08-1\end{array}$ & ith $>1 \mathrm{~s}$ \\
\hline
\end{tabular}




\section{Table 2}

New or Recurrent Bladder Tumors:

\section{After Ureteroscopic Treatment of UUTTCC}

Reference

Sowter et $\mathrm{al}^{16^{*}}$

Thompson et $\mathrm{al}^{15}$

Daneshmand et $\mathrm{al}^{14}$

Chen \& Bagley ${ }^{130}$

Combined

${ }^{*}$ No history BT

${ }^{\circ}$ reviewed series to 2001
Bladder Tumor

$12 / 35$

34.3

$37 / 83$

44.6

$6 / 30$

20.0

$41 / 101$

40.5

$96 / 249$

38.5

After Laparoscopic or Open Nephroureterectomy for UUTTCC

Reference

Rassweiler $^{17}$

Wolf ${ }^{18}$

Okegawa $^{19}$

Tsujihata ${ }^{20}$

Raman $^{21}$

Chung $^{22}$

Manabe ${ }^{23}$

Muntener ${ }^{24}$

Roupret $^{25}$

Taweemonkongsap ${ }^{26}$

Waldert ${ }^{27}$
$\%$

Laparoscopic

24.0

55

20

28

29

44

32.8

41

10

29

26
$\%$

Open

24.7

17

33

35

36

38.0

15

45

27 
Table 3

\section{Strictures after Ureteroscopic Treatment of UUTTCC}

\begin{tabular}{|c|c|c|}
\hline Reference & Patient & Stricture \\
\hline Suh et $\mathrm{al}^{28}$ & 16 & 2 \\
\hline Daneshmand et al ${ }^{14}$ & 30 & 5 \\
\hline Johnson et $\mathrm{al}^{29}$ & 35 & 3 \\
\hline Sowter et al ${ }^{16}$ & 40 & 4 \\
\hline Chen et $\mathrm{al}^{13 *}$ & 139 & 19 \\
\hline Overall & 260 & 33 \\
\hline
\end{tabular}

${ }^{*}$ combined series to 2001 